\title{
STUDI NUMERIK PRESSURE DROP PADA SILINDER TANDEM DENGAN PENAMBAHAN SPLITTER PLATE DAN VORTEX GENERATOR DI PENAMPANG SEMPIT
}

\author{
Diastian Vinaya Wijanarko \\ Teknik Mesin, Universitas Negeri Surabaya \\ 1diastianwijanarko@unesa.ac.id
}

\begin{abstract}
Abstrak - Studi numerik pressure drop pada silinder tandem dengan penambahan splitter plate dan vortex generator dengan adanya efek blockage ratio telah selesai dilakukan. Tinggi penampang dan diameter silinder pada studi ini menggunakan $\mathrm{H}=125 \mathrm{~mm}$ dan $\mathrm{D}=37,5 \mathrm{~mm}$ secara berurutan. Blockage ratio yang digunakan sebesar $30 \%$. Bilangan Reynold $(\mathrm{Re})$ yang digunakan adalah $52100 \leq \mathrm{Re} \leq 156000$. Jarak antar silinder yaitu $5 \leq \mathrm{s} / \mathrm{d} \leq 8$, dengan "s" adalah jarak dari silinder satu ke silinder dua. Dimensi splitter plate sebesar $\mathrm{L}=\mathrm{D}, \mathrm{L}=1,5 \mathrm{D}$, dan $\mathrm{L}=2 \mathrm{D}$ dengan " $\mathrm{L}$ " adalah panjang splitter plate, sedangkan untuk ketebalan splitter plate pada penelitian ini adalah $1,75 \mathrm{~mm}$. Dimensi vortex generator pada studi ini menggunakan milik Hu, dkk. [6]. Sudut vortex generator yang digunakan adalah $\theta=35^{\circ}$ sedangkan panjang vortex generator sebesar $\mathrm{H}=3 \mathrm{~mm}$. Seluruh variasi studi numerik ini dijalankan dengan metode Unsteady Reynold Average Navier Stoke (URANS). Nilai pressure drop terkecil didapatkan pada Bilangan Reynold 52.100 untuk semua variasi, sedangkan Bilangan Reynold tertinggi didapatkan pada Re 156.000. adanya penambahan splitter plate dan vortex generator, memberikan hasil pressure drop yang lebih tinggi bila dibandingkan dengan silinder sirkular.
\end{abstract}

Kata Kunci- Bilangan Reynold; blockage ratio; splitter plate; URANS; pressure drop; vortex generator.

\begin{abstract}
The numerical study of pressure drop on a tandem cylinder with the addition of a splitter plate and a vortex generator with the effect of a blockage ratio has been completed. The cross-sectional height and diameter of the cylinder in this study used $H=125 \mathrm{~mm}$ and $D=37.5 \mathrm{~mm}$, respectively. The blockage ratio is $30 \%$. The Reynolds number (Re) is $52100 \leq$ Re $\leq 156000$. The distance between cylinders is 5 to 8, where " $s$ " is the distance from cylinder one to cylinder two. The dimensions of the splitter plate are $L=D, L=1,5 D$, and $L=2 D$ where " $L "$ is the length of the splitter plate, while the thickness in this study is $1,75 \mathrm{~mm}$. The dimensions of the vortex generator in this study are used those of Hu, et al. [6]. The angle of the vortex generator is $=35^{\circ}$ while the length of the vortex generator is $H=3 \mathrm{~mm}$. All variations of this numerical study were carried out using the URANS (Unsteady Reynold Average Navier Stoke) method with a Reynolds number (Re) 52,100 Re 156,000. The smallest pressure drop value is obtained at the Reynolds number 52.100 for all variations, while the highest Reynolds number is obtained at Re 156.000. the addition of a splitter plate and a vortex generator, gives a higher pressure drop when compared to a circular cylinder.
\end{abstract}

Keywords—Reynold Number; blockage ratio; splitter plate; URANS; pressure drop; vortex generator.

\section{PENDAHULUAN}

Bluff body silinder merupakan sebuah bentuk yang paling sering ditemui dalam dunia engineering. Salah satu contoh pengaplikasian yang paling sering ditemui dalam bentuk bluff body ini ada pipa di dalam radiator. Pada umumnya terdapat aliran fluida yang melewati bluff body tersebut untuk menjalankan sistem di engineering. Beberapa sistem di engineering meletakkan konstruksi silinder di dalam penampang sempit dan terdapat sebuah aliran fluida yang melewati celah tersebut. Akibat adanya penampang sempit tersebut, maka munculnya efek blockage ratio dimana dapat mempengaruhi karakteristik aliran dari silinder tersebut. Namun terdapat beberapa kendala yang di temui apabila aliran fluida tersebut melewati bluff body berbentuk silinder, salah satunya adalah pressure drop yang tinggi.

Diastian Vinaya Wijanarko: Studi Numerik Pressure Drop...
Penelitian yang dilakukan oleh Daloglu [1] membahas tentang pressure drop pada silinder tandem dengan penambahan body pengganggu di bagian upstream dengan variasi $\mathrm{D}=\mathrm{d}, \mathrm{D}=2 \mathrm{~d}$, dan $\mathrm{D}=3 \mathrm{~d}$, serta jarak antar silinder $1,0 \leq$ $\mathrm{S} / \mathrm{d} \leq 10,0$. Bilangan Reynold yang digunakan pada penelitian ini sebesar $52100 \leq \mathrm{Re} \leq 156000$. Hasil yang didapatkan adalah semakin besar nilai bilangan Reynold, maka semakin besar pula nilai pressure dropnya. Chakrabarty, dkk. [2] melakukan eksperimen pada silinder sirkular dengan penambahan splitter plate $\mathrm{L}=\mathrm{D}, \mathrm{L}=1,5 \mathrm{D}$, dan $\mathrm{L}=2 \mathrm{D}$. Selain itu juga menambahkan V-shaped profile kedalam silinder sirkular dengan bilangan Reynold sebesar $5000 \leq \mathrm{Re} \leq 10000$. Berdasarkan hasil eksperimen, semakin besar bilangan Reynold, pressure drop yang dihasilkan juga semakin besar. Penambahan splitter plate dan V-shaped profile dapat mengurangi efek pressure drop secara signifikan. Penelitian Eksperimen penambahan splitter plate pada daerah upstream 
telah dilakukan oleh Zhou, dkk. [3]. Panjang plat yang digunakan sebesar $\mathrm{L}=3 \mathrm{D}$ pada bilangan Reynold sebesar 924 dan 2268. Zhou melaporkan bahwa dengan penambahan tersebut dapat mengurangi koefisien drag. Penelitian penambahan splitter plate juga dilakukan oleh Kwon, dkk. [4]. Variasi splitter plate yang digunakan adalah $1<\mathrm{L} / \mathrm{D}<2$ dan diletakkan pada daerah downstream. Berdasarkan hasil eksperimen, gaya drag dapat berkurang secara signifikan. Studi numerik dan eksperimen tentang penambahan splitter plate pada tube bank telah dilakukan oleh Mangrulkar, dkk. [5]. Rasio L/D yang digunakan dalam penelitian tersebut sebesar 1 dengan bilangan Reynold sebesar $5500 \leq \mathrm{Re} \leq$ 14500 yang di gunakan pada staggered tube bank. Penambahan splitter plate dapat mengurangi pressure drop dan friction faktor secara signifikan.

Penggunaan vortex generator pada silinder sirkular diteliti oleh $\mathrm{Hu}$ dkk [6]. Berdasarkan hasil studi numerik yang dilakukan, adanya penambahan vortex generator menyebabkan pengurangan friction factor.

Efek blockage ratio terhadap bluff body diteliti oleh Jiang, dkk [7]. Pada eksperimen tersebut, bluff body diletakkan pada penampang persegi empat dengan blokage ratio 9,4\% sampai dengan 59,5 \%. Jiang, dkk. Menyimpulkan bahwa semakin besar blockage ratio, maka critical velocity semakin turun.

Berdasarkan penelitian sebelumnya, penambahan splitter plate dan vortex generator dapat mengurangi kerugian didalam struktur silinder sirkular. Pada umumnya penelitian tersebut dilakukan pada tempat yang tidak memiliki efek blokage ratio. Peletakan splitter plate pada daerah upstream dengan adanya efek blockage ratio belum pernah diteliti sebelumnya. Fokus pada penelitian ini adalah melakukan sebuah studi numerik tentang pressure drop pada silinder tandem dengan penambahan splitter plate dan vortex generator di penampang sempit.

\section{METODE}

Tinggi penampang dan diameter silinder menggunakan penelitian Daloglu [1] yaitu sebesar $\mathrm{H}=125 \mathrm{~mm}$ dan $\mathrm{D}=37,5$ mm secara berurutan. Blockage ratio sebesar $30 \%$. Bilangan Reynold (Re) yang digunakan adalah $52100 \leq \mathrm{Re} \leq 156000$. Jarak antar silinder yaitu $5 \leq \mathrm{s} / \mathrm{d} \leq 8$, dengan "s" adalah jarak dari silinder satu ke silinder dua. Bentuk geometri pada studi numerik ini ditunjukkan pada gambar 1. Dimensi splitter plate menggunakan penelitian dari Chakrabarty, dkk. [2] yaitu sebesar $\mathrm{L}=\mathrm{D}, \mathrm{L}=1,5 \mathrm{D}$, dan $\mathrm{L}=2 \mathrm{D}$ dengan " $\mathrm{L}$ " adalah panjang splitter plate, sedangkan untuk ketebalan splitter plate pada penelitian ini adalah $1,75 \mathrm{~mm}$. Dimensi vortex generator pada penelitian ini menggunakan milik $\mathrm{Hu}$, dkk. [6]. Sudut vortex generator yang digunakan adalah $\theta=35^{\circ}$ sedangkan panjang vortex generator sebesar $\mathrm{H}=3 \mathrm{~mm}$. Bentuk splitter plate dan vortex generator ditunjukkan pada gambar 2 .

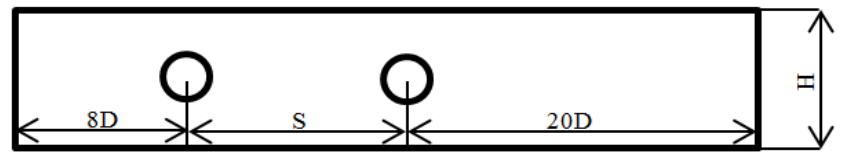

Gbr. 1 Geometry set up studi numerik silinder tandem pada penampang sempit

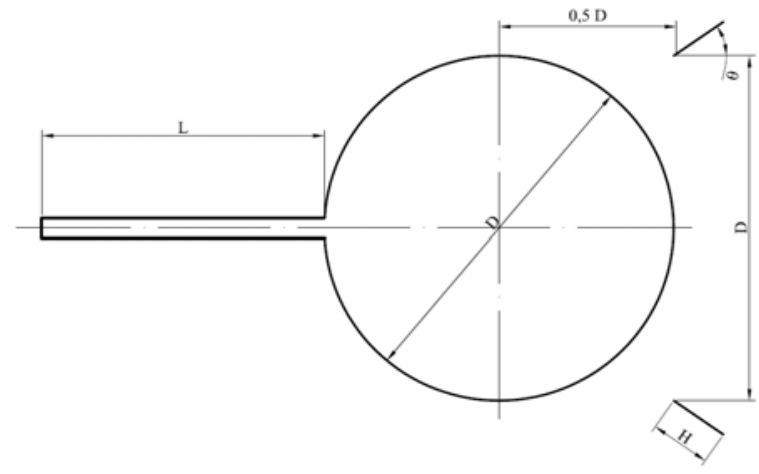

Gbr. 2 Bentuk splitter plate studi numerik silinder tandem pada penampang sempit

Simulasi numerik dilakukan dengan 2D incompressible URANS (Unsteady Reynold Average Navier Stoke) dan model turbulance viscous menggunakan k- $\omega$ Shear Stress Transport. Meshing yang digunakan dalam studi numerik ini (2-D) Quadrilateral-Map. Gambar 3 menunjukkan boundary condition dari simulasi numerik yang akan dijalankan. Bagian (a) merupakan silinder tanpa penambahan splitter plate dan vortex generator sedangkan bagian (b) merupakan silinder sirkular dengan penambahan splitter plate dan vortex generator. Bagian upstream dan downstream pada domain yang digunakan sebesar 8D dan $20 \mathrm{D}$ beruturut-turut. Bilangan Reynold yang digunakan adalah $5,21 \times 10^{4}, 7,37 \times 10^{4}$, $9,02 \times 10^{4}, 1,16 \times 10^{5}, 1,28 \times 10^{5}, 1,47 \times 10^{5}$, dan $1,56 \times 10^{5}$. Persamaan continuity dan momentum untuk adalah sebagai berikut:

$$
\frac{\partial u}{\partial x}+\frac{\partial v}{\partial y}=0
$$

Dimana $\rho$ merupakan density udara, $\mathrm{t}$ adalah waktu dan $u$ dan $v$ adalah kecepatan.

$$
\begin{aligned}
& \frac{\partial u}{\partial t}+u \frac{\partial u}{\partial x}+v \frac{\partial u}{\partial y}=-\frac{\partial p}{\partial x}+\frac{1}{\operatorname{Re}}\left(\frac{\partial^{2} u}{\partial x^{2}}+\frac{\partial^{2} u}{\partial y^{2}}\right) \\
& \frac{\partial v}{\partial t}+v \frac{\partial v}{\partial x}+v \frac{\partial v}{\partial y}=-\frac{\partial p}{\partial y}+\frac{1}{\operatorname{Re}}\left(\frac{\partial^{2} v}{\partial x^{2}}+\frac{\partial^{2} v}{\partial y^{2}}\right)
\end{aligned}
$$

Dimana $p$ merupakan static pressure, t adalah waktu, dan Re adalah bilangan Reynold. Gambar 4 menunjukkan meshing quadrilateral mesh.

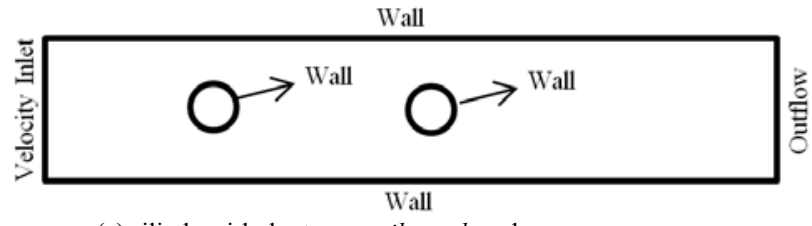

(a) silinder sirkular tanpa spiltter plate dan vortex generator 


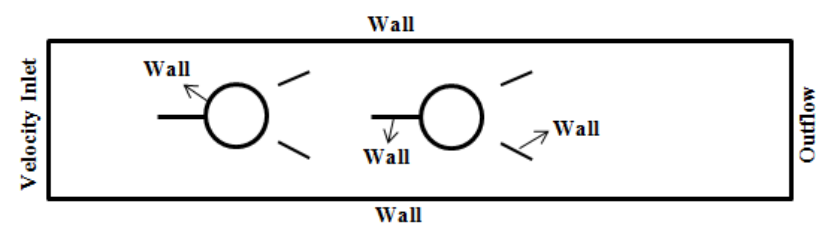

(b) Silinder sirkular dengan spiltter plate dan vortex generator Gbr 3. Boundary condition silinder tandem pada penampang sempit

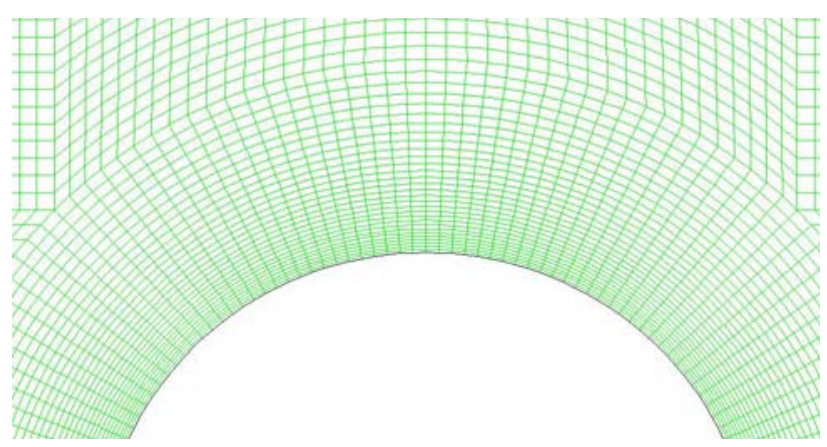

Gbr 4. Bentuk quadrilateral mesh silinder tandem pada penampang sempit

\section{Validasi numerik}

Validasi numerik yang digunakan dalam penelitian ini adalah dengan membandingkan nilai $\mathrm{Cd}$ pada salah satu variasi silinder tandem dengan kerapatan meshing yang berbeda. Pemilihan meshing pada validasi numerik nanti akan dipilih berdasarkan hasil Cd yang konstan pada tiap kerapatan meshing dan memilih meshing yang kerapatan paling kecil pada nilai Cd yang konstan tersebut. Data pembanding yang digunakan adalah silinder tanpa pengganggu. Bilangan Reynold dijalankan pada $\mathrm{Re}=116000$. Hasil validasi numerik ditunjukkan pada tabel-1. Pada tabel-1, Mesh 4 dan 5 memberikan hasil yang mirip. Oleh karena itu, maka mesh 4 dipilih sebagai meshing untuk studi nemerik ini
TABEL I

VALIDASI NUMERIK SILIDER TANDEM UPSTREAM PADA S/D 5 DENGAN RE 116000

\begin{tabular}{|c|l|l|l|}
\hline No & Meshing & Faces & Cdp \\
\hline 1. & Mesh 1 & 338170 & 0,41 \\
\hline 2. & Mesh 2 & 352570 & 0,27 \\
\hline 3. & Mesh 3 & 360350 & 0,34 \\
\hline 4. & Mesh 4 & 381370 & 0,30 \\
\hline 5. & Mesh 5 & 402340 & 0,30 \\
\hline
\end{tabular}

\section{HASIL DAN DISKUSI}

Pada pembahasan ini akan menampilkan grafik pressure drop. Variasi yang digunakan pada penelitian ini adalah jarak antar silinder dan panjang splitter plate. Sedangkan untuk vortex generatornya menggunakan dimensi yang tetap berdasarkan penelitian $\mathrm{Hu}$ [7]. Gambar 5 menunjukkan grafik pressure drop dengan variasi s/d. Pada variasi tersebut, dapat dilihat bahwa terjadi perbedaan nilai pressure drop di tiap variasi s/d maupun Bilangan Reynold. Gambar 5a menunjukkan hasil numerik pada silinder sirkular. Pada grafik tersebut, nilai pressure drop terkecil didapatkan pada Bilangan Reynold 52.100, sedangkan nilai tertinggi didapatkan pada Bilangan Reynold 156.000. Adanya variasi s/ d menyebabkan perbedaan pola grafik hasil yang menarik ditunjukkan pada Bilangan Reynold 147.000 dan 156.000 dimana terjadi penurunan pressure drop pada s/d 7. Gambar 5 $\mathrm{b}$, c, dan d grafik variasi pressure drop pada penambahan splitter plate $\mathrm{D} ; 1,5 \mathrm{D}$; dan 2D. Masing-masing grafik menunjukkan pola grafik yang unik dimana mayoritas grafik menunjukkan bahwa semakin panjang variasi s/d, maka semakin besar pula nilai pressure drop. Namun, ditemukan sebuah fenomena yang menarik dimana variasi split 1,5 D dengan Bilangan Reynold 156.000 menunjukkan pola yang berkebalikan dmana pressure drop semakin menurut akibat penambahan s/d.

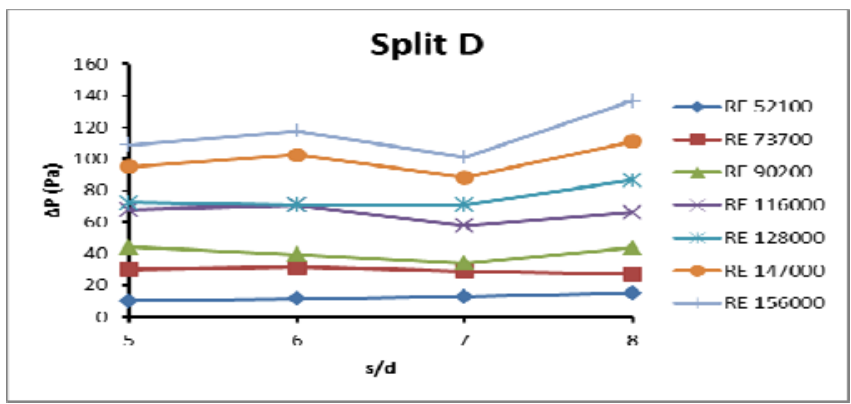

(b) (a)

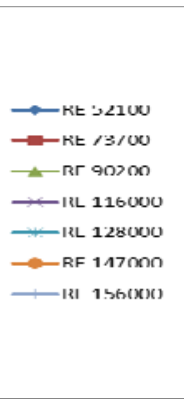




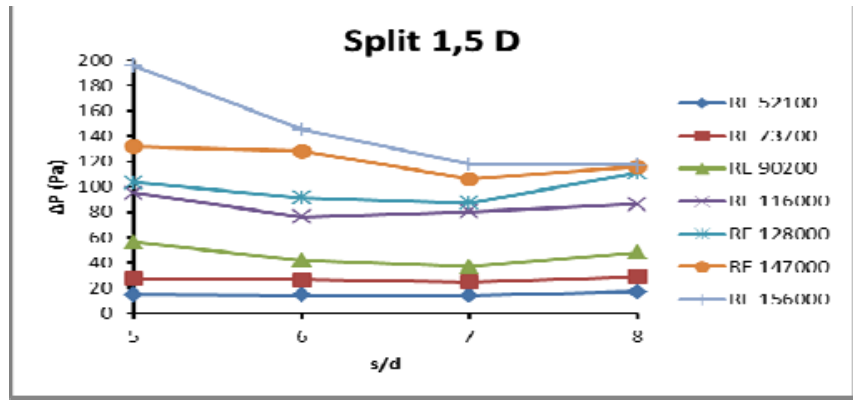

(c)

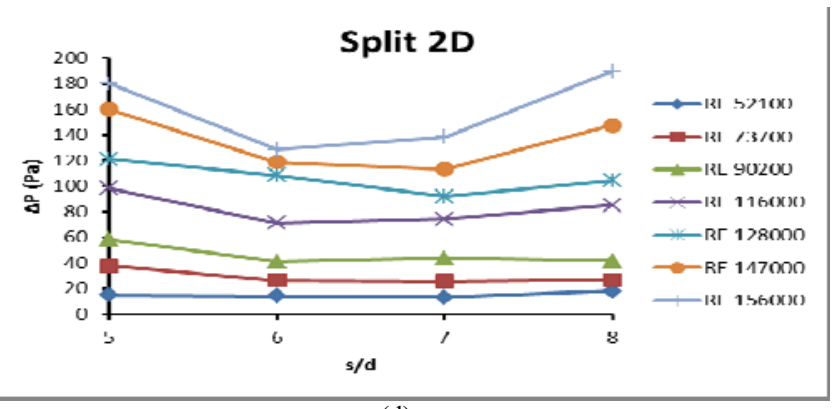

(d)

Gbr. 5 Grafik variasi pressure drop dengan variasi s/d

Gambar 6 menunjukkan grafik variasi pressure drop dengan Bilangan Reynold. Fenomena yang unik akibat adanya efek blockage ratio dapat diketahui dengan bertambahnya pressure drop sebanding dengan bertambahnya Bilangan Reynold. Pada gambar 6a dengan variasi silider sirkular, ratarata nilai pressure drop terkecil di tunjukkan oleh s/d 8 . Sedangkan rata-rata pressure terbesar ditunjukkan pada s/d 5 . Grafik pressure drop terhadap bilangan reynold dengan variasi s/d 5, 6, 7, 8 ditunjukkan pada gambar 6 b, c, d, dan e secara berurutan. Dengan adanya penambahan splitter plate dan vortex generator, memberikan hasil pressure drop yang lebih tinggi bila dibandingkan dengan silinder sirkular. Pola grafik pada penambahan splitter plate dan vortex generator mengalami kenaikan berbanding lurus dengan kenaikan Bilangan Reynold. Pressure drop tertinggi ditujukkan pada variasi splitter plate dan vortex generator dengan $\mathrm{s} / \mathrm{d} 8$.

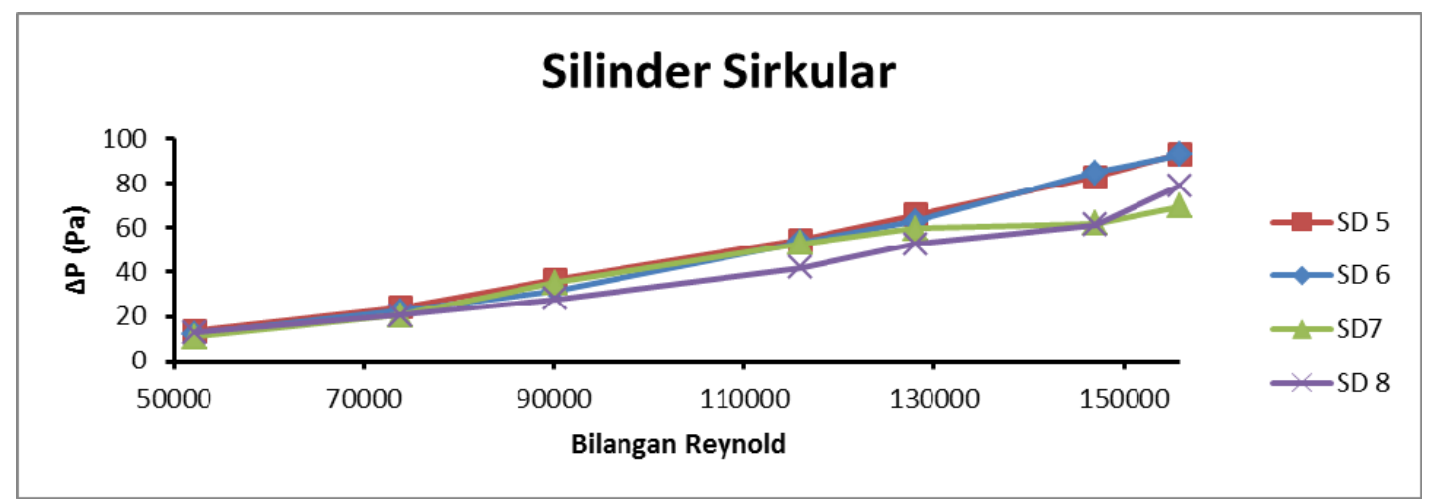

(a)

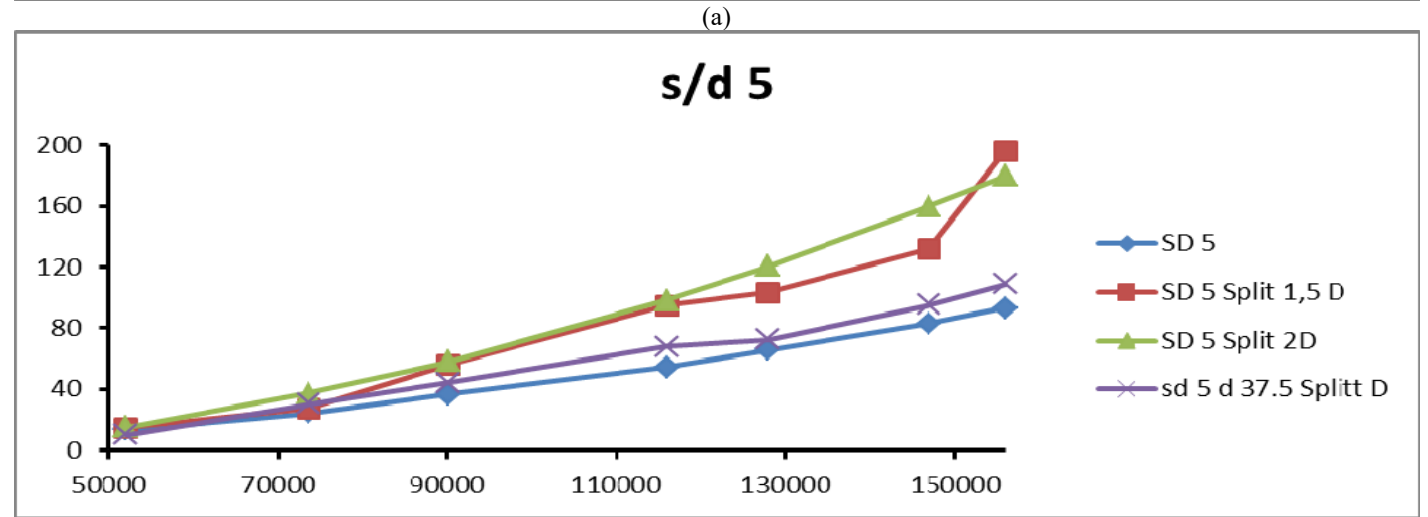

(b)

Diastian Vinaya Wijanarko: Studi Numerik Pressure Drop... 

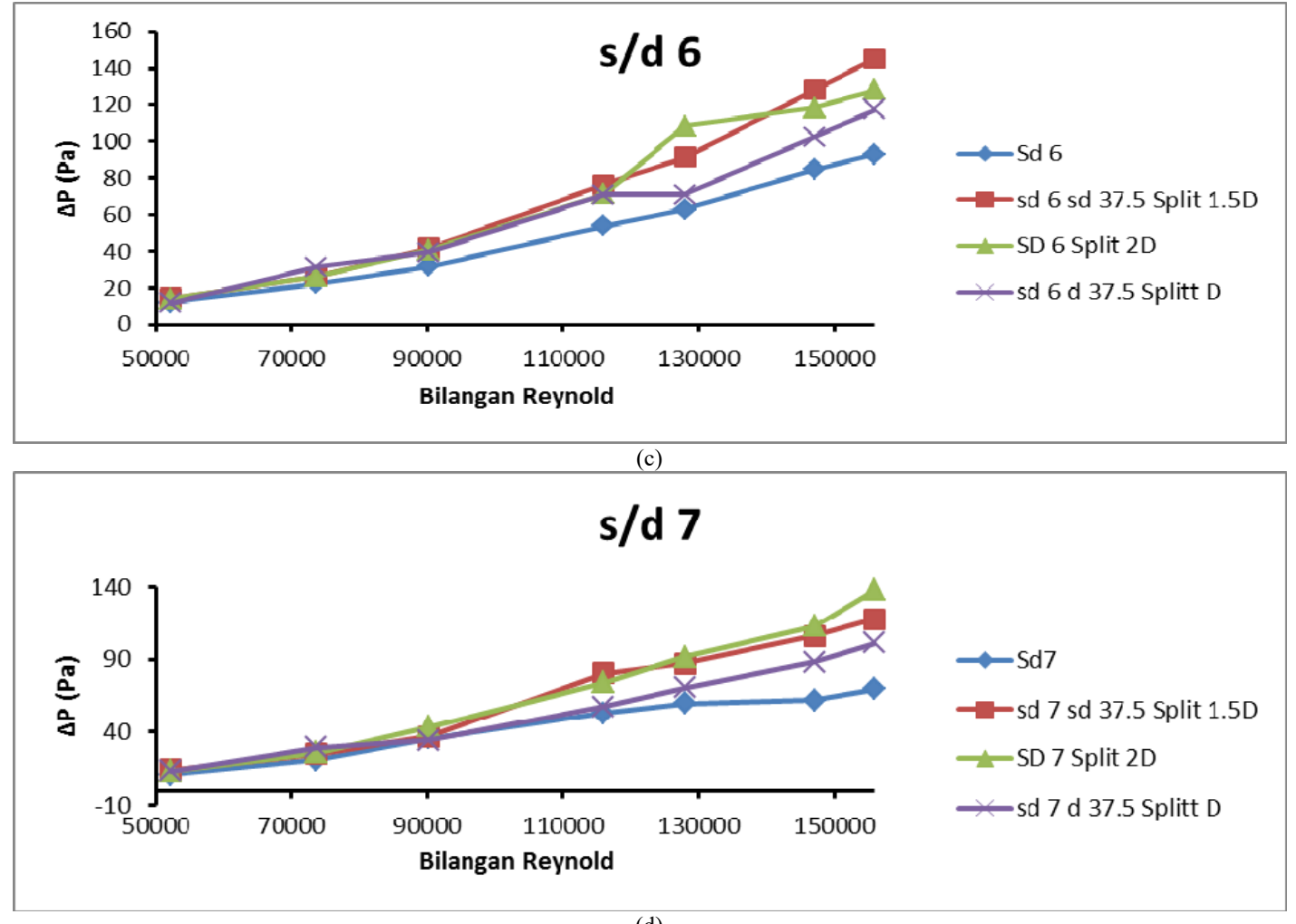

(d)

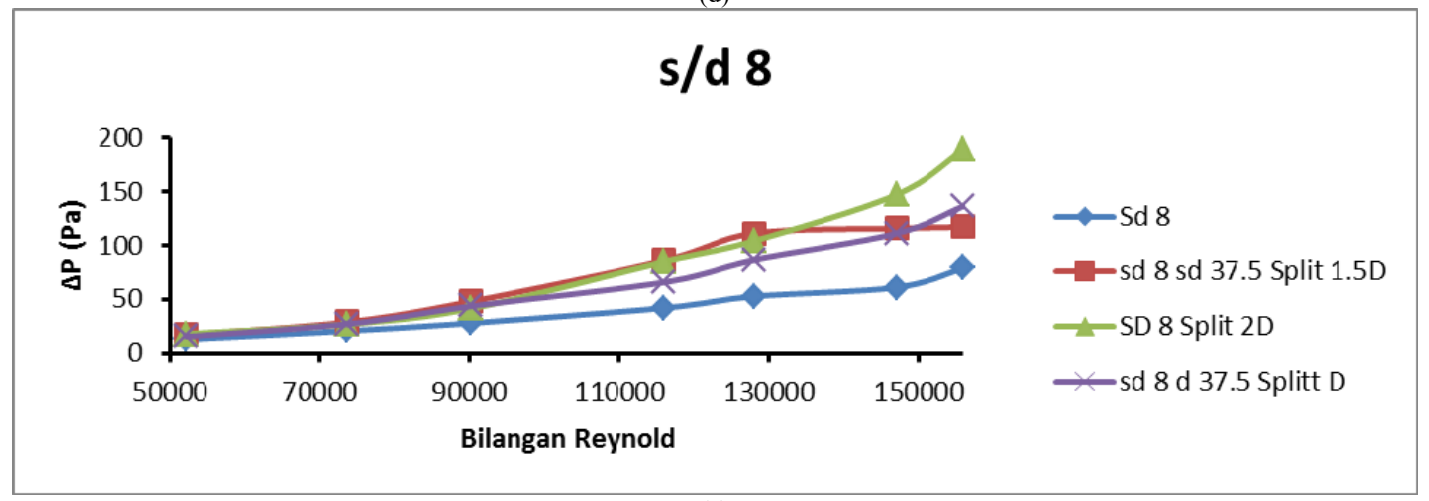

(e)

Gbr. 6 Grafik variasi pressure drop dengan Bilangan Reynold

KESIMPULAN

Berdasarkan hasil studi numerik yang telah dilakukan pada silinder tandem dengan penambahan splitter plate dan vortex generator di penampang sempit, disimpulkan bahwa Nilai pressure drop terkecil didapatkan pada Bilangan Reynold 52.100 untuk semua variasi, sedangkan Bilangan Reynold tertinggi didapatkan pada Re 156.000 . Adanya penambahan splitter plate dan vortex generator, memberikan hasil pressure drop yang lebih tinggi bila dibandingkan dengan silinder sirkular pada saluran sempit.

\section{REFERENSI}

[1] A. Daloglu, "Pressure drop in a channel with cylinders in tandem arrangement," Int. Commun. Heat Mass Transf., vol. 35, no. 1, pp. 76-83, 2008.

[2] S. G. Chakrabarty, A. H. Yadav, and K. N. Wagh, "Experimental Analysis of Heat Transfer and Pressure drop Behaviour of a Circular Cylinder with Passive Flow Control Technique," Int. J. Appl. or Innov. Eng. Manag., vol. 2013, no. Ratmig, 2013.

[3] X. Zhou, J. J. Wang, and Y. Hu, "Experimental investigation on the flow around a circular cylinder with upstream splitter plate," J. Vis., vol. 22, no. 4, pp. 683-695, 2019.

[4] K. Kwon and H. Choi, "Control of laminar vortex shedding behind a circular cylinder using splitter plates," Phys. Fluids, vol. 8, no. 2, pp. 479-486, 1996. 
[5] C. K. Mangrulkar, A. S. Dhoble, S. G. Chakrabarty, and U. S. Wankhede, "Experimental and CFD prediction of heat transfer and friction factor characteristics in cross flow tube bank with integral splitter plate," Int. J. Heat Mass Transf., vol. 104, pp. 964-978, 2017.

[6] W. Hu et al., "The optimum fin spacing of circular tube bank fin heat exchanger with vortex generators," Heat Mass Transf. und Stoffuebertragung, vol. 49, no. 9, pp. 1271-1285, 2013.

[7] X. Jiang, H. Zhang, and A. Jing, "Effect of blockage ratio on critical velocity in tunnel model fire tests," Tunn. Undergr. Sp. Technol., vol. 82, no. May, pp. 584-591, 2018. 